\title{
Intergenerational Well-Being Mobility in Europe
}

\author{
José Alberto Molina, María Navarro and Ian Walker*
}

\section{INTRODUCTION}

The analysis of intergenerational persistence of economic status is crucial for the design of social policies that attempt to equalise opportunities and increase mobility across generations. These policies aim to increase the independence of children from their parents' income position, to minimise disadvantages being transferred from one generation to the next. As a result, intergenerational income mobility has generated a considerable literature. The standard approach to studying this issue is to estimate correlations of lifetime earnings of parents and children (Blinder, 1976; Solon, 1992; Zimmerman, 1992; Hammarstedt, 2009). Furthermore, not only income but other types of intergenerational links, such as transmission of education, have been shown to exist (Chevalier, 2004; Farré et al., 2009).

There has been decreasing satisfaction with a narrow income-based measure of well-being (see Stiglitz et al., 2009) and this has not yet been reflected in the literature on intergenerational mobility. Here, we are interested in studying intergenerational mobility using well-being, rather than income alone. Studying well-being provides an opportunity to examine intergenerational mobility in a broader sense. This is both important and informative as parents make long-term decisions that are not based solely on considerations of children's potential income, but more broadly their utility and wellbeing (Corak, 2006). Moreover, these considerations may be influenced by their own wellbeing rather than current earnings alone. In order to do this, we use satisfaction

* Correspondence to: José Alberto Molina. University of Zaragoza and IZA. Tel.:0034976761818. Fax.:0034976761818. jamolina@unizar.es. María Navarro Paniagua, Economics Department, Lancaster University Management School and FEDEA, Lancaster LA1 4YX, UK. E-mail: m.navarro paniagua@lancs.ac.uk. Ian Walker, Economics Department, Lancaster University and IZA, Lancaster LA1 4YX, UK. E-mail: ian.walker@lancs.ac.uk. The authors would like to thank Colin Green for helpful comments. We are grateful to the Editors and two anonymous referees for suggestions that improved the paper. Alberto Molina thanks the Spanish Ministry of Science (project ECO2008-01297) and Maria Navarro gratefully acknowledges the Spanish Ministry of Science and Innovation Postdoctoral Grant 2008-0583 and CYCIT project ECO2008-06395-C0503/ECON for their financial support. 
variables that have been shown to be valid measures of individual well-being in the happiness literature (Frey and Stutzer 2002a; 2002b; Layard, 2005; Van Praag and Ferrer-i-Carbonell, 2008). In particular, we use representative European data to estimate correlations between children's and parents' satisfaction via responses to questions about satisfaction with income as proxy measures of the economic well-being of individuals. Previous studies of parents' and children's subjective well-being correlations do not seek to examine the intergenerational transmission of well-being, but rather are concerned with the altruism of parents toward their children (Schwarze, 2004; Schwarze and Winkelmann, 2005). The only exception is the work of Winkelmann (2005), which exploits panel data for Germany and, using a hierarchical random effects model, attributes $44 \%$ of the variance in individual's well-being to unobserved characteristics common to the family.

Thus, the contribution of this paper is to provide empirical evidence of the extent of intergenerational well-being mobility for the countries of the EU-15. We deal with the potential endogeneity bias of the transmission parameter by exploiting the presence of heteroskedasticity in a cross-sectional setting, using rank-order IV and conditional second moments (henceforth CSM) estimation. OLS and panel (Fixed Effects and First Differences) models are also estimated, providing the upper and lower bounds for the true causal effect.

Our results suggest higher intergenerational correlations of economic wellbeing in Greece, Portugal, Italy, Spain where variations in parental well-being are transmitted more fully to children, leading to a significant lack of mobility in those countries. Lower coefficients in Finland, Denmark, the Netherlands, Belgium and the UK, indicate that differences in well-being do not persist across generations, and thus these societies are more mobile.

Our country ranking of the intergenerational mobility of economic wellbeing is generally in line with the ranking of the intergenerational transmission of earnings that can be derived from previous country-specific studies. But the UK provides a stark exception. The UK, normally located in the middle in terms of income mobility, is found to be in the group of most mobile countries when it turns to well-being mobility. Denmark and Finland (Bratsberg et al., 2007) show the highest mobility across generations. In an intermediate position, we observe Germany (Couch and Dunn, 1997), Spain (SánchezHugalde, 2004), France (Lefranc and Trannoy, 2005) and the United Kingdom (Dearden et al., 1997; Bratsberg et al., 2007), whereas Italy (Piraino, 2007), along with Greece and Portugal, exhibit the lowest degrees of intergenerational income mobility within the EU. ${ }^{1}$

1. The bulk of empirical evidence is based on US data. Comparative studies reveal that the US is the country with the highest intergenerational persistence (Bratsberg et al., 2007; Corak, 2006). 
The remainder of the paper is organised as follows. The next section outlines the data and samples used (Fathers, Mothers, Fathers-Sons, Fathers-Daughters, Mothers-Sons, and Mothers-Daughters). In Section 3, we briefly describe the rank-order IV and CSM procedures. Section 4 presents the results on intergenerational well-being mobility, and the final section presents our conclusions.

\section{DATA}

Our empirical analysis employs data from the European Community Household Panel, a representative longitudinal survey conducted by Eurostat from 1994 to 2001 for the countries of the EU $15 .{ }^{2}$ In this survey, households and the individuals living in them who are 16 years old or older are interviewed in the first wave, and are followed for the remaining years. ${ }^{3}$ An appealing feature of this data set is that it enables us to identify parents and their children and, thus, allows us to observe the correlations of parents' and children's economic well-being. Moreover, data are harmonised and comparable, allowing us to make cross-country comparisons of the degree of well-being transmission between generations.

We select families in which both the parent and the child of 16 or older, still living at home, and provide non-missing responses to the question about their income satisfaction. We study six different samples - Fathers, Mothers, Fathers-Sons, Fathers-Daughters, Mothers-Sons and Mothers-Daughters in order to determine whether the transmission mechanism is stronger depending on the gender of parents and children.

Our dependent variable is a young adult's satisfaction with his/her financial situation, which is our proxy measure of individual economic well-being. The high correlation between financial and overall satisfaction in both the BHPS and the GSOEP, suggests that our findings are likely to also apply to a more general measure of well-being. ${ }^{4}$ The specific question we employ, based on individual perceptions, is: 'How satisfied are you with your present financial situation?' with the responses taking values from 1, 'not satisfied at all' to 6, 'completely satisfied'. The mean and standard deviation of responses are shown in Figure 1 and in the first and second row of the corresponding sample Tables. Those individuals in Denmark, the Netherlands, Luxembourg, Belgium and Austria report the highest satisfaction scores on average; whereas fathers and mothers in Southern Europe (Greece, Spain, Portugal and Italy) report the lowest. Then, when we compare fathers and mothers declared

2. Sweden is excluded from our analysis, since the Swedish ECHP files do not contain satisfaction data.

3. Austria and Finland joined the survey in 1995 and 1996, respectively.

4. Van Praag et al., 2003 find that the effect of financial on general satisfaction is $0.637,0.859,0.760$ and 0.890 for the samples of German West workers, East workers, West non-workers and East nonworkers, respectively. 


\section{JOSÉ ALBERTO MOLINA/MARÍA NAVARRO/IAN WALKER}

Figure 1

Mean of Parents and Children Income Satisfaction in each of the countries
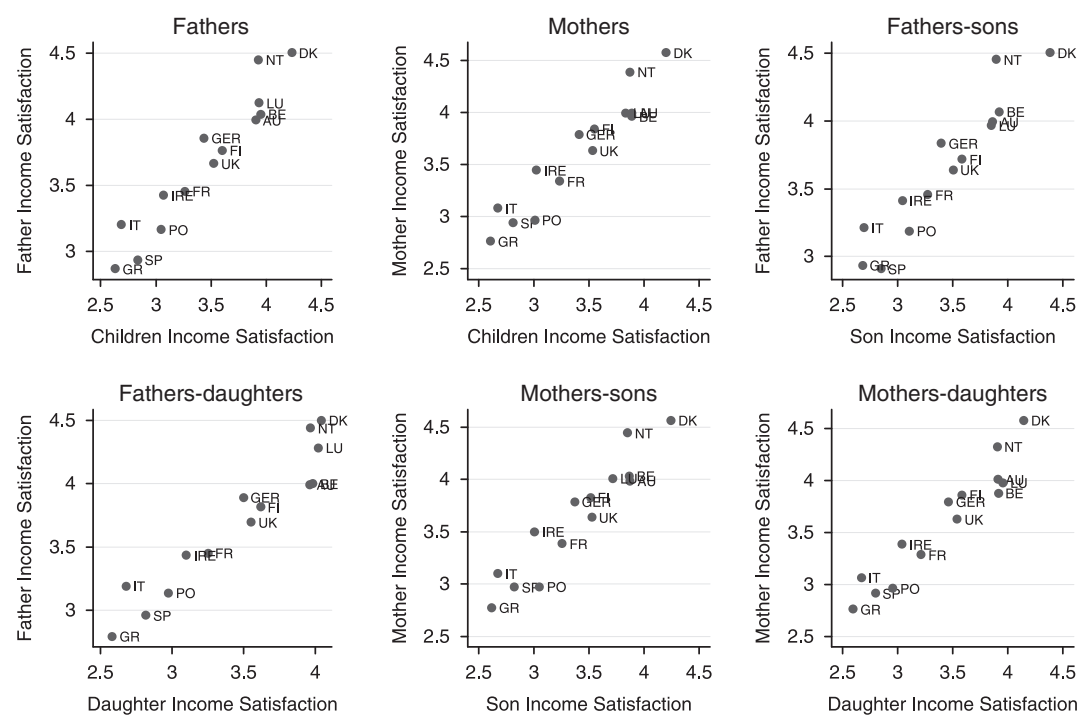

income satisfaction, we observe that the average hardly varies, although it is slightly smaller for the mothers in most of the sample countries. However, if the comparison is between generations, we observe that in each of the samples, parents declare higher income satisfaction than their children no matter whether they are sons or daughters.

We assume implicit cardinalisations of the dependent variable (Child IncWell-being), which is discrete and ordinal, and of our main regressor (Parental IncWell-being). This procedure (Probit Ordinary Least Squares POLS) has been shown to generate very similar results to those of ordinal analysis (Van Praag and Ferrer-i-Carbonell, 2008). ${ }^{5}$

With respect to the explanatory variables, our study includes a number of parent and child individual characteristics that have been shown to be important determinants of individual subjective well-being in previous research (Clark and Oswald, 1994; Frey and Stutzer, 2006; Sousa-Poza and Sousa-Poza, 2000). Thus, we incorporate socio-demographic variables, including the age and the age squared of the parent and the child (ParentAge, ChildAge, ParentAgeSq, ChildAgeSq), the education level of the parent and that of the child (ParentPrimEduc, ParentSeconEduc, ParentHighEduc,

5. Ferrer-i-Carbonell and Frijters (2004) and Clark and Senik (2010) also find that assuming cardinality or ordinality does not change the results. 
ChildPrimEduc, ChildSeconEduc, ChildHighEduc), and two variables that indicate the marital status of the parent and of the child (ParentMarried, ChildMarried). The study also includes labour market variables denoting whether the parent and the child are inactive or unemployed (ParentInactive, ChildInactive, ParentUnemployed, ChildUnemployed), and when they are employed, whether they are white-collar workers (ParentWhitecollar, ChildWhitecollar).

In addition, we examine two household characteristics, with the first indicating the number of individuals in the household (HouseholdSize), and the second corresponding to the net wage of both parents and children (ParentalNetWage, ChildNetWage). ${ }^{6}$

We restrict our samples to children between 16 and 24 years old living in the household. Those who are over 24 years old are excluded to avoid overrepresenting children who left home at a later age. This is more important in some countries than in others, because the pattern of leaving home varies markedly across countries in Europe. The number of observations for each of the samples is shown in the last row of the Tables. We conduct an attrition analysis to make sure that there is no overestimation of the intergenerational transmission coefficient due, for instance, to more (or less) income-satisfied children leaving the household. ${ }^{7}$

\section{METHODOLOGY}

In the following model, we estimate correlations between son's or daughter's economic well-being, which we denote $W_{i t}^{C}$, and that of his/her parent, $W_{i t}^{P}$, in order to calculate the intergenerational transmission of economic well-being from parents to children:

$$
\begin{gathered}
W_{i t}^{C}=\beta_{1} W_{i t}^{P}+\beta_{2} X_{i t}^{C}+\beta_{3} X_{i t}^{P}+\varepsilon_{i t} \\
W_{i t}^{P}=\delta_{1} X_{i t}^{P}+v_{i t}
\end{gathered}
$$

where $\beta_{1}$ indicates the degree of intergenerational persistence, whereas $\left(1-\beta_{1}\right)$ constitutes a measure of intergenerational well-being mobility. The lower $\beta_{1}$,

6. Parental and child net monthly wage is expressed in PPP terms, and refers to the year 2001.

7. We find that children of less income satisfied parents are more likely to leave the home in Greece and Portugal, in Belgium in the case of daughters, Finland in the sample of mothers and daughters, and Ireland in the mothers and sons sample. We also find that less income-satisfied daughters are more likely to leave the household in France, more income-satisfied children are more likely to leave the household in Greece for the father's samples, and in Portugal for the sample of mothers and sons, whereas no effect is found in the remaining countries. However, when we take into account sociodemographic, labour and economic characteristics, joint with time dummies, there is no significant effect of dropping out of the sample for those children, or children born to parents in the highest or lowest categories of the satisfaction distribution, compared to those in the middle categories. 
the higher the mobility and thus, the child's well-being is more independent of that of his/her parent. Whereas the higher $\beta_{1}$, the greater is parental well-being transmitted to the next generation.

$X_{i t}^{C}$ and $X_{i t}^{P}$ are vectors of children's and parent's exogenous variables, respectively. The error terms, $\varepsilon_{i t}$ and $v_{i t}$, are likely to be correlated, and thus, OLS estimates of $\beta_{1}$ on the children's well-being equation are not consistent, due to the fact that there are factors that are correlated with parental economic well-being that also affect the children's economic well-being. These factors comprise social connections that ease access to education and jobs for the next generation; ability or family culture; and investments that influence skills, beliefs and motivations.

The common solution to overcome this problem of consistency is to find an exogenous source of variation in parental well-being that identifies $\beta_{1}$. However, it is difficult to think of any obvious exclusion restriction that affects a child's economic well-being simply via its effect on parental economic wellbeing, as it seems reasonable that parental characteristics directly influence both parent's and child's economic well-being.

In the absence of a reasonable exclusion restriction, we seek to identify the causal effect of $W^{P}$ on $W^{C}$, by exploiting the presence of heteroskedasticity in the model. This methodology has been used by Rummery, Vella and Verbeek (1999), Klein and Vella (2009) and Hogan and Rigobon (2003) to estimate the returns to education for Australian youths, Australian workers, and UK males, respectively.

Recent studies on mobility are concerned with the possibility of downward bias in $\beta_{1}$ due to un-representative samples, measurement error, and because we typically observe parents and children at different points in their respective life-cycles. First, the fact that the ECHP data comes from a national probability sample avoids the homogeneity of the samples used in some previous studies (where the variance of the dependent variable was smaller than in a representative sample population). Second, economic well-being is considered a better measure for long-run economic status than the short-run proxies generally used, as it has been shown to be highly dependent on education outcomes, health status, income, and household wealth. Income satisfaction is likely to be a more stable measure of economic well-being that does not reflect unobserved transitory fluctuations normally included in the single-year measures of income or earnings. Third, we include a second-order polynomial in age (age, age squared) for both parent and child, to account for the fact that child economic well-being is observed at an earlier stage of the life-cycle than that of the parent.

\section{Rank-order IV}

This approach attempts to account for the endogeneity of parental economic well-being, $W^{P}$, in the child's economic well-being equation, without the 
availability of exclusion restrictions in a cross-sectional framework, using the rank-order instrumental variable procedure of Vella and Verbeek (1997).

To address this issue, we first allocate the data set into $\mathrm{S}$ exclusive subsets on the basis of the region of residence in each of the sample countries. The order restriction is likely to be fulfilled with the former variable. ${ }^{8}$

We estimate the reduced form equation for parental economic well-being (Equation 2) and obtain the residuals, $\hat{v}_{i}$, which are used to order the observations within each subset. We then normalise the index by dividing the rank-order value for each observation by the total number of observations in its own subset, leading to a normalised rank-order variable which we denote by $c_{i}$.

We then estimate Equation (1) using a linear polynomial of the nonparametric estimate of $c_{i}$ as an instrumental variable for parental economic well-being. Therefore, we are able to identify the transmission of economic well-being from parents to children by comparing parents in one subset with the parents in similar areas of the distribution of unobserved heterogeneity in other subsets of the data. ${ }^{9}$

\section{Conditional second moments}

The second approach applies the parametric specification of heteroskedasticity of Klein and Vella's (2010) conditional second moment estimator, developed by Farré et al. (2009). ${ }^{10}$

The approach adopted assumes that: $(i)$ the intergenerational transmission of unobservables is invariant to the individuals' socio-economic environment, with this implying that the conditional correlations between the homoskedastic error terms are constant. This seems reasonable if unobserved ability, (inherited) optimism, or anchoring of responses are transferred from parents to children somehow genetically (see De Neve et al., 2010) and thus they are independent of the parents' and child's environment; (ii) the vectors $X_{i t}^{C}$ and $X_{i t}^{P}$ are exogenous; (iii) $\varepsilon_{i t}$ and $v_{i t}$ are heteroskedastic ${ }^{11}$ and, due to the fact that we are using a parametric approach, we must also make an assumption about the functional form of such heteroskedasticity. The conditional variance functions are assumed to be of an exponential form: $H_{v i}^{2}=\exp \left(G_{v i} \theta_{2}\right)$ and $H_{\varepsilon i}^{2}=\exp \left(Z_{\varepsilon i} \theta_{1}\right)$.

8. The order restriction requires that the order of observations reflects the endowment of unobserved heterogeneity. It imposes that a parent in a certain position in one region reduced form error distribution is similar to the parent in the same rank-order in other regions, with the corresponding distribution of unobserved ability being similar across regions.

9. The other required assumption is that parents located in the same area of the distribution of unobserved heterogeneity (parents with similar rank-order values) in different regions report different income satisfaction levels.

10. They estimate the returns to education and the intergenerational transmission of schooling, both for the US.

11. At least one of the equation's error terms needs to be heteroskedastic. 
We estimate the following control function model by non-linear least squares:

$$
W_{i}^{C}=\beta_{1} W_{i}^{P}+\beta_{2} X_{i}^{C}+\beta_{3} X_{i}^{P}+\rho \frac{H_{\varepsilon i}}{\hat{H}_{v i}} \hat{v}_{i}+u_{i}
$$

where $\hat{v}_{i}$ corresponds to the residual from the parent's economic well-being equation (2). $\hat{H}_{v i}$ is calculated as the standard deviation of the reduced form error $H_{v i}=\sqrt{\exp \left(G_{v i} \hat{\theta}_{2}\right)}$, where $\hat{\theta}_{2}$ are estimated parameters obtained from regressing the logarithm of the squared residuals of Equation (2) on G, the vector of variables responsible for the heteroskedasticity in the parent's economic wellbeing equation. The former vector includes age and parental education, a variable that indicates whether the parent was born in another country, and regional dummies. $H_{\varepsilon i}$ is calculated in two different ways (Control Function 1 and Control Function 2 in the Tables). In the first, Equation (3) requires the estimation of $H_{\varepsilon i}=\sqrt{\exp \left(Z_{\varepsilon i} \theta_{1}\right)}$ through the minimum of a least squares problem related to $W^{C}$, whereas the second estimates the parameters $\hat{\theta}_{1}$, as in the parental economic well-being equation. $\mathrm{Z}$ is the vector of variables that produce the heteroskedasticity in the child's economic well-being equation, comprised by the gender of the child in the first two samples, whether the child was born in another country, and regional variations.

\section{RESULTS}

We estimate separate regressions of parent's and children's income satisfaction by country, which allows us to investigate cross-country differences in intergenerational economic well-being mobility. Tables 1 to 4 show the estimated coefficients of well-being transmission for the samples of the pairs of fathers and sons, fathers and daughters, mothers and sons and mothers and daughters. The tables for the samples of fathers and mothers are available from the authors upon request.

We first treat parental economic well-being as an exogenous variable and estimate the child's economic well-being equation using OLS (Equation 1). These results constitute our upper bound estimates and are reported in rows 1 and 2 of Panel B in Tables 1-4. We observe that, after we include the child's characteristics and parental variables likely to affect children's economic wellbeing, the coefficient in row 2 (our preferred specification) decreases from that in row 1 in each of our samples, save in Denmark.

In order to reduce the contaminating effect of unobserved individual heterogeneity, we also exploit the longitudinal structure of the ECHP. First differences and fixed effects models are estimated for our preferred specification, shown in rows 3 and 4 of Panel B in Tables 1-4, respectively. These results 
INTERGENERATIONAL WELL-BEING MOBILITY IN EUROPE

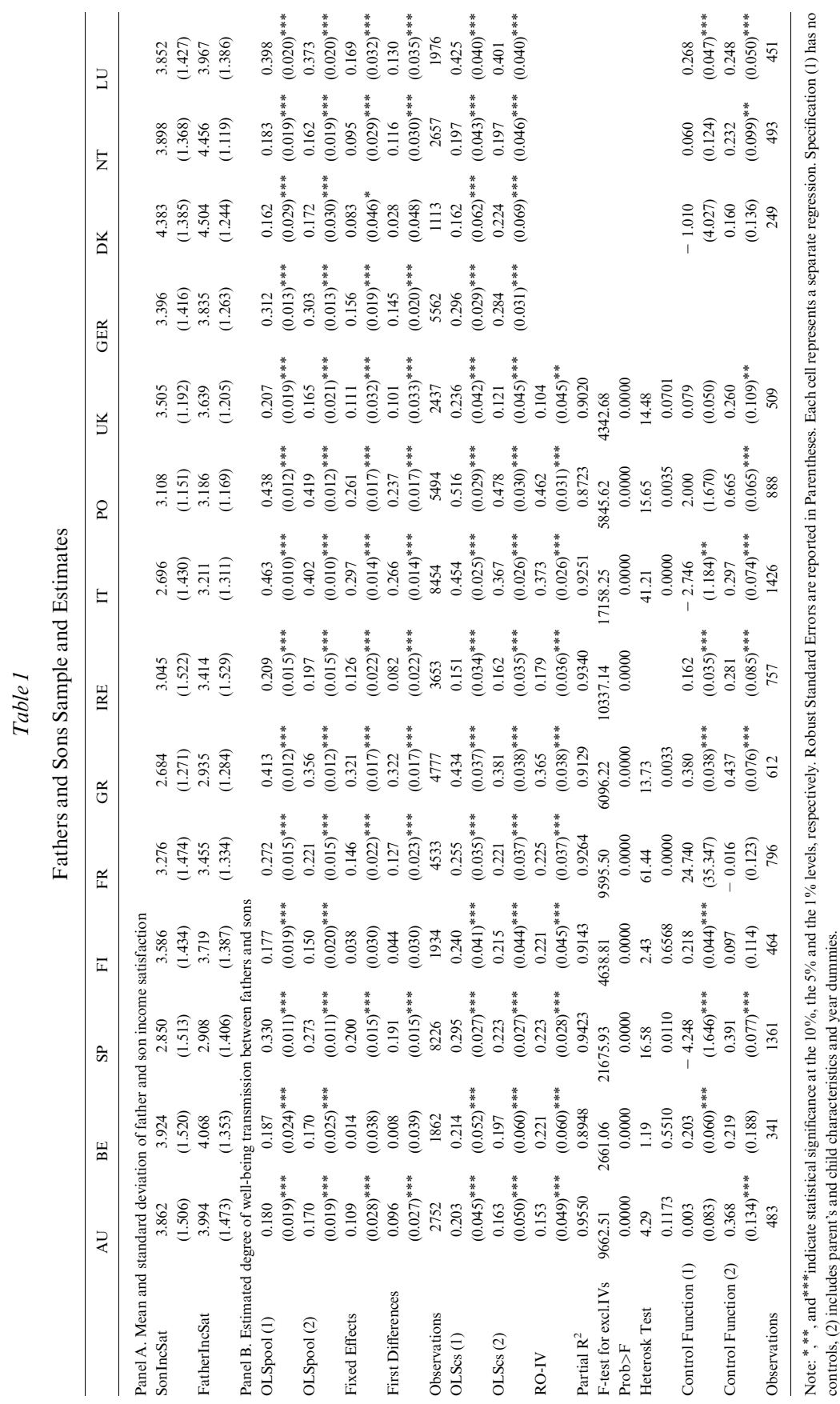




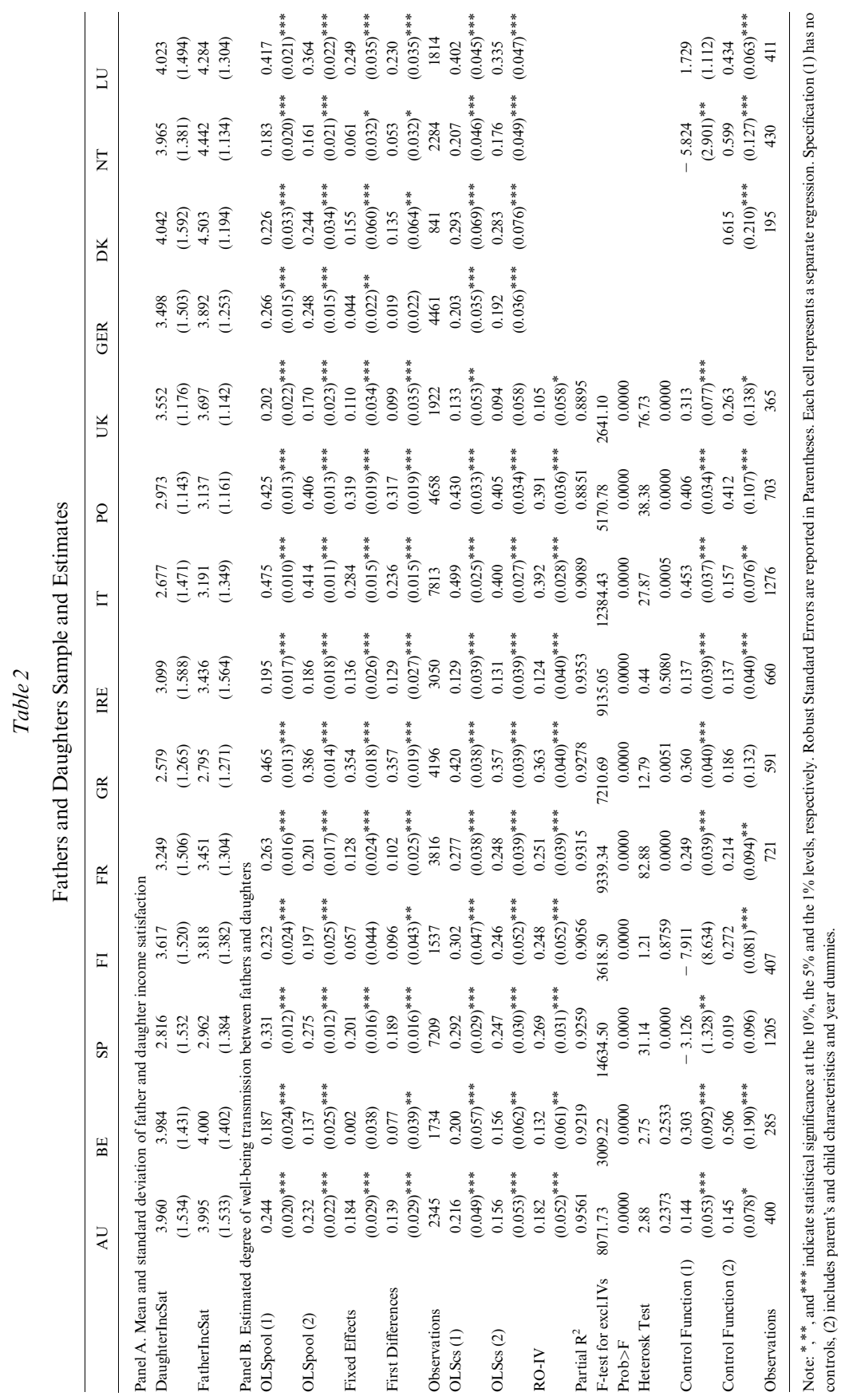


INTERGENERATIONAL WELL-BEING MOBILITY IN EUROPE

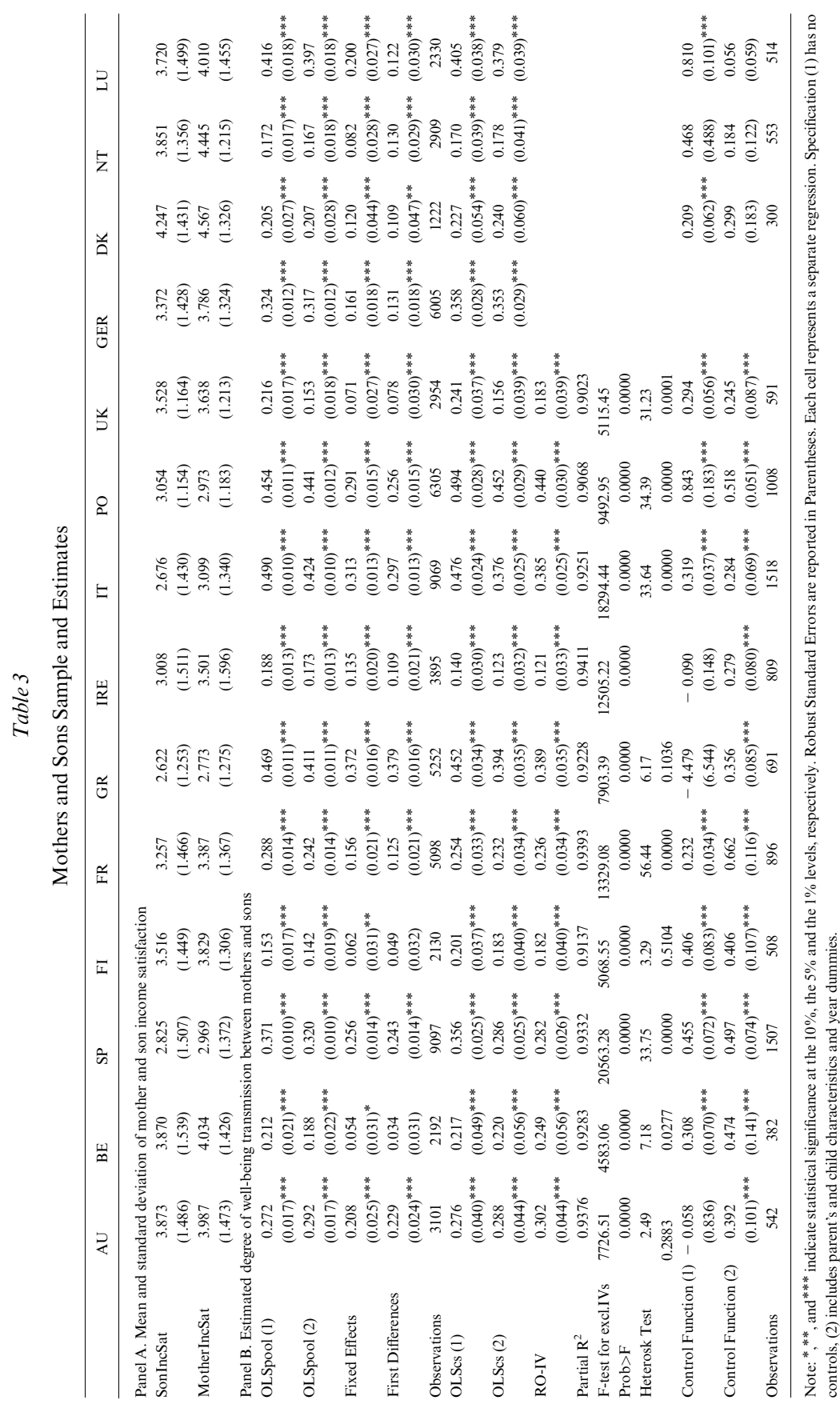




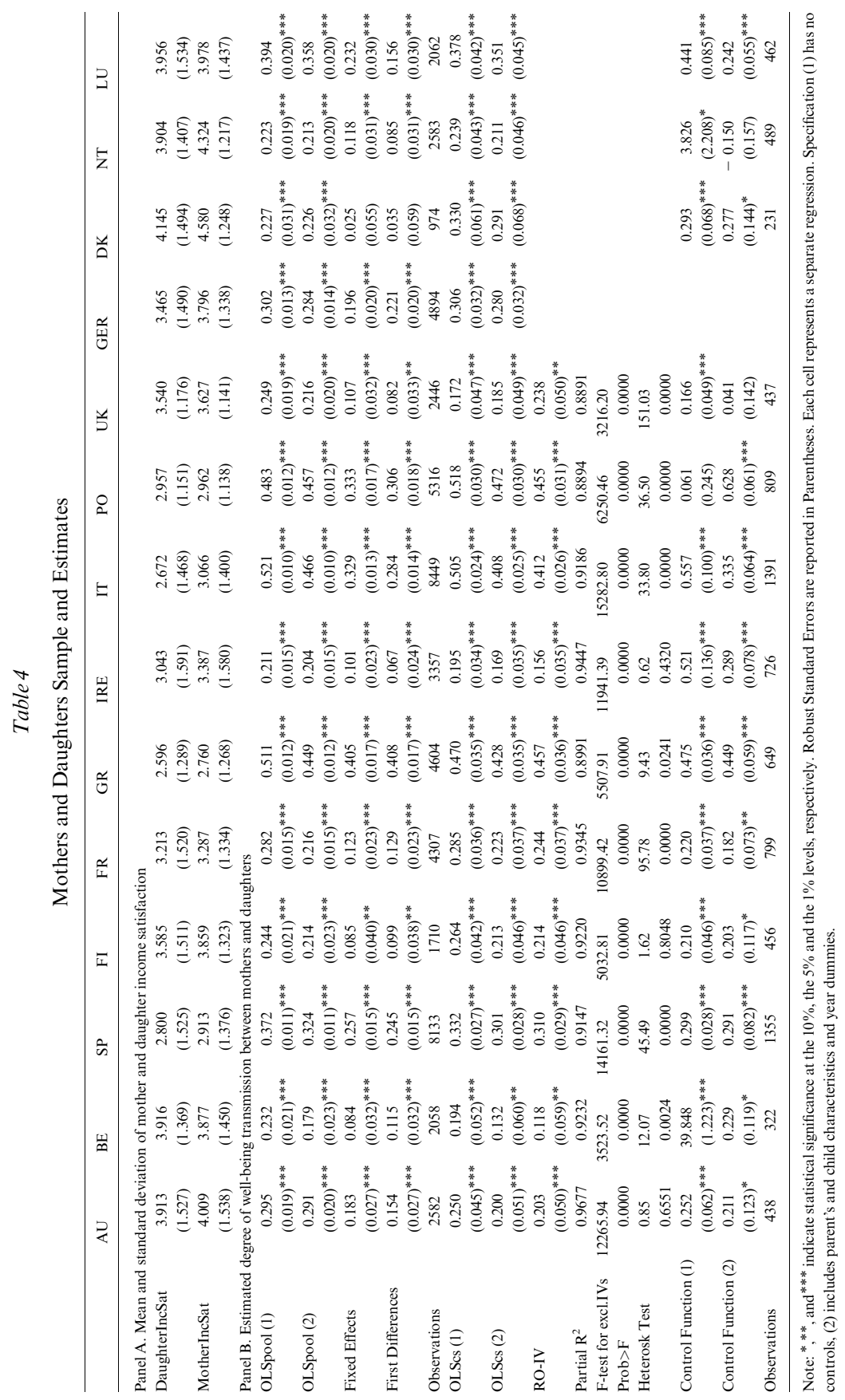


Figure 2

FD, Rank-order IV and OLS estimates of the intergenerational well-being transmission by country in each of the samples
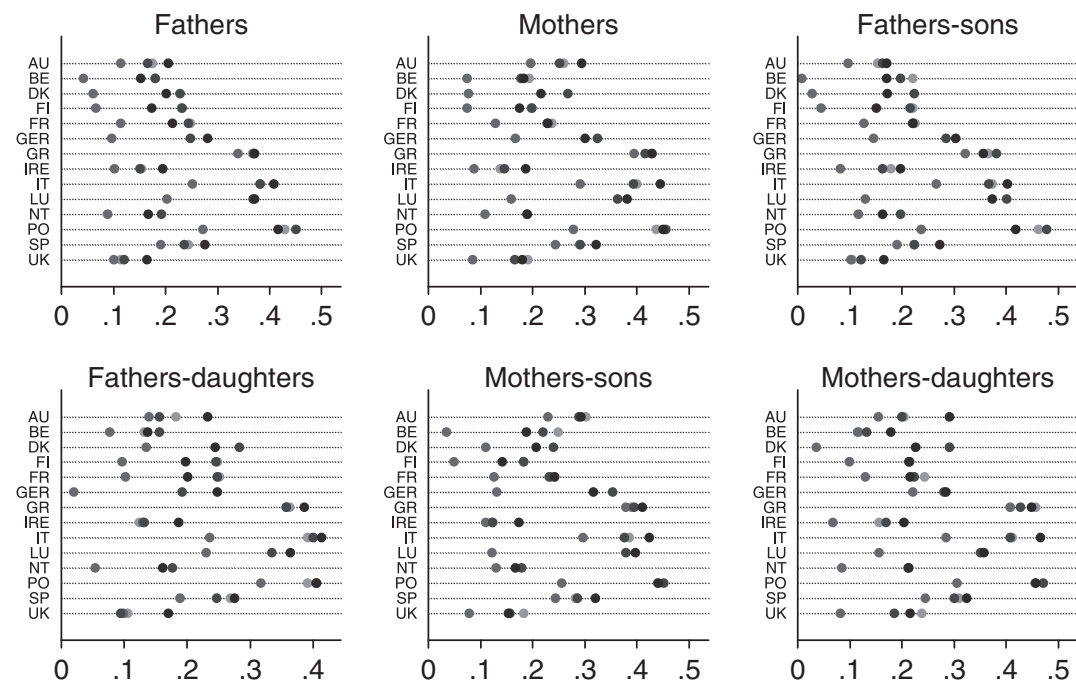

$\bullet$ OLSpool $\bullet$ OLScs $\bullet$ FD $\bullet$ RO-IV

are significantly lower than the previous OLS estimates, which can be compared in Figures 2 and 3. Thus, they provide our lower bound estimates since FE and FD are biased towards zero due to the fact that there is more measurement error in the differenced regressors than in their levels (Angrist and Pischke, 2009, pp. 225-226).

From row 5 onwards, we present a cross-sectional structure, keeping one observation only for each parent and child pair. Rows 5 and 6 correspond to our OLS estimates without and with child and parent characteristics.

Our estimates of intergenerational mobility may suffer from endogeneity bias insofar as there are unobserved factors such as inherited ability and optimism that may have a direct effect, not only on parental but also on child economic well-being. In row 7, we present the results where we consider parental well-being as endogenous and we instrument it with the parent's position in the error distribution in each region. The partial $\mathrm{R}^{2}$ and F-test for exclusion restrictions, and the corresponding $\mathrm{p}$-values, indicate that the chosen instrument is strong. Moreover, we regress the squared residuals on the regional dummies and a constant to test for heteroskedasticity. The null hypothesis of no region-related heteroskedasticity is rejected for the majority of the samples and countries. 
Figure 3

FD, Control Function and OLS estimates of the intergenerational well-being transmission by country in each of the samples
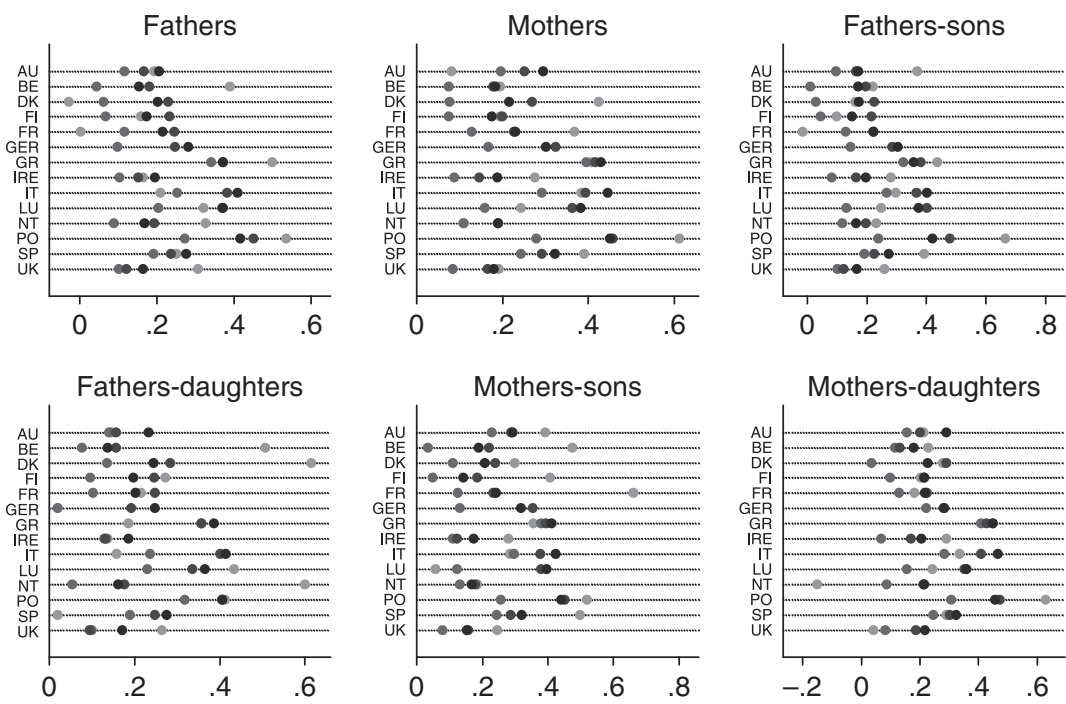

$\bullet$ OLSpool $\bullet$ OLScs $\bullet$ FD $\bullet$ CF2

The ranking of the estimated coefficients for all the estimation methods implemented are generally in line with that found in the literature on income mobility. Southern European countries (Portugal, Italy and Greece) and Spain $^{12}$ to a lesser extent, are much more persistent in economic well-being across generations than Northern European countries (Finland, Denmark, the Netherlands, Belgium and the UK), which appear to be the most mobile. This suggests that the latter countries have been much more successful in equalising life opportunities for children regardless of their family background. Other Continental countries, such as France, Austria, Germany and Luxembourg, as well as Ireland, are situated in an intermediate position.

Differences arise between, rather than within, countries where the pattern is very similar for the different samples. When we look at the differences within countries for each of the different samples, we observe that the intergenerational well-being transmission is determined to a greater extent by mothers than by fathers. The exception is Ireland, where the opposite applies, as it

12. Although in Spain individuals report higher income satisfaction levels, they break the Southern European pattern regarding immobility. 
occurs in Sweden (Österberg, 2000). The persistence of the differences between mothers and fathers within the same country is quite large in Austria, Greece, Spain, Germany and the UK.

In the case of fathers, the relative persistence of intergenerational mobility between sons and daughters is not clear, but rather depends on the estimation methods. Fathers affect daughters more than sons in Austria, Denmark, Finland, Spain and the UK (as has been found by Dearden et al., 1997, for the UK), while Austria and Denmark are the countries with the greatest differences. Big differences are seen in Germany where son's economic status is much more persistent than daughter's with respect to their father's economic well-being (as found previously for Germany by Couch and Dunn (1997)).

In the father's graph of Figure 2, we observe that the rank order IV estimate for Greece is very high, 0.367 , much closer to the OLS estimate $(0.370)$ than to the first difference estimate (0.339). The transmission coefficient is much lower in the UK (0.114), where it lies between the FD (0.100) and the OLS $(0.120)$ estimates. These numbers are very close to those in the sample of fathers and sons for the UK 0.104, located between 0.101 (FD) and 0.121 (OLS). For the father's sample in Figure 3, we observe that the control function estimate is 0.157 in Finland and is situated between the FD $(0.066)$ and the OLS estimates (0.232). In Luxembourg, the coefficient is 0.320 , between 0.203 (FD) and 0.368 (OLS), where we observe that mobility is higher from fathers to sons (0.248), lying between 0.130 (FD) and 0.401 (OLS).

In the sample of fathers and sons the FD estimate in Austria (0.096) constitutes the lower bound for the rank-order IV coefficient (0.153), whereas the OLS estimate is very close to the upper bound (0.163). However, mobility from fathers to daughters is slightly higher, as reflected by the coefficient of the control function approach (0.145), which lies between the FD (0.139) and the OLS estimate (0.156). For their part, fathers in Italy seem to transmit 0.297 of their well-being to their sons using the CF estimate (between 0.266 (FD) and 0.367 (OLS)). However, the persistence of economic well-being towards their daughters is higher when we look at the rank-order IV procedure $(0.392$, between 0.236 and 0.400 ). It is also worth mentioning other cases such as Belgium, which is ranked as one of the most mobile countries between fathers and daughters (0.132, RO-IV), and Portugal which is ranked as one of the lowest in terms of mobility with 0.391 (RO-IV), for the same sample.

To determine the degree of persistence between mothers and their children we focus on the case of mothers and daughters. Economic well-being is transmitted more strongly to daughters than to sons in Greece, Portugal, Spain, Italy, ${ }^{13}$ Finland and the UK (see Dearden et al., 1997 for the UK). The exceptions are Austria and Belgium, where mothers seem to affect sons more

13. As expected, there is evidence of the opposite for Italian sons only in the FD models. 
than daughters (where differences are especially large), as found in Couch and Dunn (1997) for Germany and the US. In Figure 2, and row 7 of Table 4, we observe the causal effect in Belgium (0.118), Ireland (0.156) and Portugal (0.455) when using the rank of the mother in the error distribution within a region as an IV for parental economic well-being. In Figure 3 and row 9 of Table 4, we observe the control function estimate for very persistent countries such as Luxembourg (0.242), Spain (0.291) and Italy (0.335). However, as one of the most mobile countries, Finland (0.203) is bounded between the FD (0.099) and the OLS estimate (0.213), whereas for an intermediate country, such as France (0.182), it lies between the FD (0.129) and the OLS estimation (0.223).

The results regarding the usual correlates of individual subjective well-being, not reported for brevity but available on request, confirm that young adult economic well-being is indeed higher for those children with higher net wages, for white-collar workers, and for the children born to white-collar workers, especially in the sample of fathers and daughters. As often found, well-being is U-shaped in age (Blanchflower and Oswald, 2007) and the unemployed and the inactive are less income-satisfied than young adults who are employed (Chadi, 2010; Clark and Oswald, 1994).

\section{CONCLUSIONS}

This paper models intergenerational well-being mobility in 14 European Union countries. In particular, OLS and panel estimates provide the upper and lower bound estimate of the causal effect of parental economic well-being on that of children. The latter is obtained employing the rank-order IV and conditional second moments estimates, exploiting the presence of heteroskedasticity in the data.

Our study provides empirical evidence, not only for a sample of fathers and sons, but for pairs of fathers and daughters, mothers and sons, and mothers and daughters, separately. Our findings suggest that Southern European countries (Portugal, Italy and Greece) are much more persistent in well-being across generations than Finland, Denmark, the Netherlands and the UK. Spain breaks the Southern European pattern and Luxembourg, although coming next in the immobility ranking, behaves significantly different to the former countries. Another difference to the ranking established by the studies on intergenerational earnings mobility is the UK, situated in an intermediate position in income terms, seems more mobile in terms of well-being transmission.

We observe that differences arise between countries rather than for different subsamples within the same country. Intergenerational wellbeing transmission is determined to a greater extent by mothers than by fathers. And it is transmitted more strongly from mothers to daughters than to sons in Greece, Portugal, Spain, Italy, Finland and the UK. 
Future research should analyze not only the degree of immobility in a country but also its trend. Moreover, other two aspects such as assortative mating and asymmetries within countries, which are important in the intergenerational process of income transmission, would be interesting to explore in the well-being context.

\section{REFERENCES}

Angrist, Joshua D. and Jörn-Steffen Pischke (2009). Mostly Harmless Econometrics: An Empiricist's Companion. Princeton University Press.

Blanchflower, David G. and Andrew J. Oswald (2007). Is Well-being U-Shaped over the Life-Cycle? NBER Working Paper 12935.

Blinder, Alan S. (1976). Inequality and Mobility in the Distribution of Wealth, Kyklos. 29(4): 607-638.

Bratsberg, Bernt, Knut Røed, Oddbjørn Raaum, Robin Naylor, Markus Jäntti, Tor Eriksson and Eva Österbacka (2007). Nonlinearities in Intergenerational Earnings Mobility: Consequences for Cross-Country Comparisons, Economic Journal. 117: C72-C92.

Chadi, Adrian (2010). How to Distinguish Voluntary from Involuntary Unemployment: On the Relationship between the Willingness to Work and Unemployment-Induced Unhappiness, Kyklos. 63(3): 317-329.

Chevalier, Arnaud (2004). Parental Education and Child's Education: A Natural Experiment, IZA Discussion Paper 1153.

Clark, Andrew E. and Andrew J. Oswald (1994). Unhappiness and Unemployment, Economic Journal. 104: 648-659.

Clark, Andrew E. and Claudia Senik (2010). Who Compares to Whom? The Anatomy of Income Comparisons in Europe, Economic Journal. 120: 573-594.

Corak, Miles (2006). Do Poor Children become Poor Adults? Lessons from a Cross Country Comparison of Generational Earnings Mobility, Research on Economic Inequality. 13: 143-88.

Couch, Kenneth A. and Thomas A. Dunn (1997). Intergenerational Correlations in Labor Market Status: A Comparison of the United States and Germany, Journal of Human Resources. 32: 210-232.

Dearden, Lorraine, Stephen Machin and Howard Reed (1997). Intergenerational Mobility in Britain, Economic Journal. 107: 47-66.

De Neve, Jan-Emmanuel, Nicholas A. Christakis, James H. Fowler and Bruno S. Frey (2010). Genes, Economics, and Happiness, CESifo Working Paper Series 2946.

Farré, Lídia, Roger Klein and Francis Vella (2009). Does Increasing Parents' Schooling Raise the Schooling of the Next Generation? Evidence Based on Conditional Second Moments, IZA Discussion Paper 3967.

Ferrer-i-Carbonell, Ada and Paul Frijters (2004). How important is methodology for the estimates of the determinants of happiness?, Economic Journal. 114: 641-659.

Frey, Bruno S. and Alois Stutzer (2002a). What can Economists Learn from Happiness Research?, Journal of Economic Literature. 40: 402-435.

Frey, Bruno S. and Alois Stutzer (2002b). Happiness and Economics: How the Economy and Institutions Affect Human Well-being. Princeton, NJ: Princeton University Press.

Frey, Bruno S. and Alois Stutzer (2006). Does marriage make people happy, or do happy people get married?, The Journal of Socio-Economics. 35: 326-347.

Hammarstedt, Mats (2009). Intergenerational Mobility and the Earnings Position of First-, Second-, and Third-Generations Immigrants, Kyklos. 62(2): 275-292.

Hogan, Vincent and Roberto Rigobon (2003). Using Heteroscedasticity to Estimate the Returns to Education, University College Dublin School of Economics Working Paper 200301. 


\section{JOSÉ ALBERTO MOLINA/MARÍA NAVARRO/IAN WALKER}

Klein, Roger and Francis Vella (2009). Estimating the Return to Endogenous Schooling Decisions for Australian Workers via Conditional Second Moments, Journal of Human Resources. 44: 1047-1065.

Klein, Roger and Francis Vella (2010). Estimating a class of triangular simultaneous equations models without exclusion restrictions, Journal of Econometrics. 154: 154-164.

Layard, Richard (2005). Happiness: Lessons From a New Science. New York: Penguin Press.

Lefranc, Arnaud and Alain Trannoy (2005). Intergenerational earnings mobility in France: Is France more mobile than the U.S.?, Annales d'Economie et de Statistique. 78, pages 03, Avril-Jui.

Österberg, Torun (2000). Intergenerational Income Mobility in Sweden: What Do Tax-Data Show?, Review of Income and Wealth. 46: 421-36.

Piraino, Patrizio (2007). Comparable estimates of intergenerational income mobility in Italy, The B.E. Journal of Economic Analysis \& Policy. 7(2).

Rummery, Sarah, Francis Vella and Marno Verbeek (1999). Estimating the returns to education for Australian youth via rank-order instrumental variables, Labour Economics. 6: 491-507.

Sánchez-Hugalde, Adriana (2004). Movilidad intergeneracional de ingresos y educativa en España (1980-90), Institut d'Economia de Barcelona, Centre de Recerca en Federalismo Fiscal i Economia Regional Working Paper 2004/1.

Schwarze, Johannes (2004). Living Conditions of Children and Parental Well-being: Evidence from German Data on Life Satisfaction, IZA Discussion Paper 1200.

Schwarze, Johannes and Rainer Winkelmann (2005). What Can Happiness Research Tell Us About Altruism? Evidence from the German Socio-Economic Panel, IZA Discussion Paper 1487.

Solon, Gary (1992). Intergenerational Income Mobility in the United States, American Economic Review. 82: 393-408.

Sousa-Poza, Alfonso and Andres A. Sousa-Poza (2000). Taking Another Look at the Gender/Job Satisfaction Paradox, Kyklos. 53(2): 135-152.

Stiglitz, Joseph E., Amartya Sen and Jean-Paul Fitoussi (2009). The measurement of economic performance and social progress revisited, Documents de Travail de l'OFCE 2009-33, Observatoire Francais des Conjonctures Economiques (OFCE).

Van Praag, Bernard M.S. and Ada Ferrer-i-Carbonell (2008). Happiness Quantified: A Satisfaction Calculus Approach. Revised Edition. Oxford University Press: Oxford, UK.

Van Praag, Bernard M.S., Paul Frijters and Ada Ferrer-i-Carbonell (2003). The anatomy of subjective well-being, Journal of Economic Behavior and Organization. 51: 29-49.

Vella, Francis and Marno Verbeek (1997). Using rank order as an instrumental variable: an application to the return to schooling, CES Discussion Paper 97.10, K.U. Leuven.

Winkelmann, Rainer (2005). Subjective Well-Being and the Family: Results from an Ordered Probit Model with Multiple Random Effects, Empirical Economics. 30: 749-761.

Zimmerman, David J. (1992). Regression Toward Mediocrity in Economic Structure, American Economic Review. 82: 409-429.

\section{SUMMARY}

This paper provides evidence of the intergenerational mobility of economic wellbeing for the countries of the EU-15. We deal with the potential endogeneity of the transmission parameter by exploiting the presence of heteroskedasticity in a cross-sectional setting, using rank-order IV and conditional second moments estimation. OLS and panel (Fixed Effects and First Differences) models are also estimated, providing the upper and lower bounds for the true causal effect, not only for fathers and sons, but also for fathers and daughters, mothers and sons and mothers and daughters, in each of the sample countries. Our findings suggest that income well-being is much more persistent across generations in Southern European countries than in Finland, Denmark, the Netherlands and the UK. 